\title{
Extraction of rosmarinic acid from Melissa officinalis L. by heat-, microwave- and ultrasound-assisted extraction techniques: A comparative study through response surface analysis
}

\author{
Cristina Caleja $^{\mathrm{a}, \mathrm{b}, \mathrm{c}}$, Lillian Barros ${ }^{\mathrm{a}, \mathrm{b}}$, M.A. Prieto ${ }^{\mathrm{a}, \mathrm{d}}$, Maria Filomena Barreiro ${ }^{\mathrm{b}}$, M. Beatriz P.P. Oliveira ${ }^{\mathrm{c}}$, \\ Isabel C.F.R. Ferreira ${ }^{\mathrm{a}, *}$ \\ ${ }^{a}$ Mountain Research Centre (CIMO), ESA, Polytechnic Institute of Bragança, Campus de Santa Apolónia, 1172, 5300 -253 Bragança, Portugal \\ ${ }^{\mathrm{b}}$ Laboratory of Separation and Reaction Engineering - Laboratory of Catalysis and Materials (LSRE-LCM), Bragança Polytechnic Institute, Bragança, Portugal \\ ${ }^{\mathrm{c}}$ REQUIMTE/LAQV, Faculty of Pharmacy, University of Porto, Rua Jorge Viterbo Ferreira, no. 228, 4050-313 Porto, Portugal \\ ${ }^{\mathrm{d}}$ Nutrition and Bromatology Group, Faculty of Food Science and Technology, University of Vigo, Ourense Campus, E32004 Ourense, Spain
}

\section{A R T I C L E I N F O}

Article history:

Received 12 May 2017

Received in revised form 12 June 2017

Accepted 12 June 2017

Available online 14 June 2017

\section{Keywords:}

Heat-/microwave-/ultrasound- assisted extraction

Melissa officinalis L.

Response surface methodology

Rosmarinic acid

\begin{abstract}
A B S T R A C T
The goal of this study was to compare the extraction of rosmarinic acid from Melissa officinalis L. using three techniques (heat- -, microwave- and ultrasound- assisted extraction). In order to obtain the conditions that maximize the rosmarinic acid extraction, a response surface methodology was applied using the circumscribed central composite design of three variables with five levels. The relevant independent variables used for the process optimization were time, temperature and ethanol-water proportion for heat-assisted- and microwave-extration, whereas for the ultrasound method the ultrasonic power was variable. The responses used as criteria were the amount of rosmarinic acid was determined by HPLCDADand the extraction yield of the obtained residue. Ultrasound extraction proved to be the most effective method, capable of yielding $86.3 \pm 4.1 \mathrm{mg}$ rosmarinic acid/g plant per dry weight $(\mathrm{dw})$ at the optimal extraction conditions ( $33.0 \pm 3.2 \mathrm{~min}, 371.7 \pm 19.3 \mathrm{~W}$ and $39.9 \pm 1.4 \%$ of ethanol). According to the content of rosmarinic acid, microwave- and heat-assisted extractions techniques were less effective, producing $49.4 \pm 2.3$ (at $26.5 \pm 2.1 \mathrm{~min}, 108.6 \pm 10.2^{\circ} \mathrm{C}$ and $25.5 \pm 0.9 \%$ of ethanol) and $59.4 \pm 2.2$ (at $106.2 \pm 5.1 \mathrm{~min}, 88.0 \pm 2.9^{\circ} \mathrm{C}$ and $34.5 \pm 1.6 \%$ of ethanol), respectively. Additionally, the solid/liquid ratio effect at the optimal values in a dose-response format was studied in view of its plausible transference at industrial level, showing a decreasing non-linear pattern from 5 to $120 \mathrm{~g} / \mathrm{L}$. In brief, the obtained results highlight the potential applications of using the leaves from M. officinalis as a source of rosmarinic acid.
\end{abstract}

(c) 2017 Elsevier B.V. All rights reserved.

\section{Introduction}

Melissa officinalis L. (lemon balm) is a plant of the Lamiaceae family that has been consumed since several decades in form of decoction, infusion or directly in food $[1,2]$. It is a millenarian plant popularly known for presenting multiple benefits to consumer's well-being. This has aroused great interest among researchers to prove these same properties scientifically [3]. In addition to the recognized effects in assisting digestion problems, rheumatism or headaches, several studies have demonstrated their antioxidant, hypoglycemic, hypolipidemic, antimicrobial, anticancer, antidepressant, anxiolytic, anti-inflammatory and spasmolytic capabilities $[4-8]$.

\footnotetext{
* Corresponding author.

E-mail address: iferreira@ipb.pt (I.C.F.R. Ferreira).
}

Such beneficial effects of $M$. officinalis extracts may be primarily attributed to the presence of phenolic compounds [1]. Scientific research revealed that this plant contains various phytochemicals including terpenes (mono-terpenes, sesquiterpenes and triterpenes) and phenolic compounds (phenolic acids, flavonoids and tannins) [3,9]. Argyropoulos and Müller [10] have revealed that the main active compounds of lemon balm are volatiles (e.g. geranial, neral, citronellal and geraniol), triterpenes (e.g. ursolic acid and oleanolic acid), and phenolic compounds (e.g. cis and trans rosmarinic acid isomers, caffeic acid derivatives, luteolin, naringin and hesperidin). However, rosmarinic acid (RA) has been identified by many authors as the most abundant phenolic compound $[1,10,11]$ and, recently, a direct relationship has been established between the presence of phenolic acids (mainly hydroxycinnamic acid derivatives such as RA) and the in vitro bioactivities demonstrated by $M$. officinalis extracts $[1,12,13]$. 
Due to consumers pressure because of the issues that are involved with several undesirable effects of synthetic compounds on human health, the food industry is being forced to seek for alternatives [11]. Natural-derived alternatives from plant extracts with proven benefits are being incorporated into food matrices in order to partially or totally replace those synthetic additives. As a consequence, the food industry has invested in solutions based on plants, mushrooms and algae, to be used as natural ingredients, which can act as food additives (e.g. by increasing shelf-life) and, simultaneously, bring health benefits, since they retain the original natural bioactivity of the natural sources [14].

The production of natural ingredients needs preliminary studies concerning the isolation of these compounds and the establishment of the best extraction methodology and conditions [15,16]. Although a wide variety of solid-liquid extraction procedures is available to obtain natural ingredients, the use of extended time periods of extraction, the need of large amounts of solvents and the partial loss of natural molecules (such as phenolic compounds) was some of the disadvantages identified by some authors, like as $[15,17]$.

Heat-assisted extraction (HAE) is the conventional method mostly used for the extraction of natural compounds. Its advantage is the simplicity of its procedure, whereas its disadvantage is related with the extended periods of extraction and the high temperatures required [18]. Ultrasound-assisted extraction (UAE) is an alternative extraction method that has been pointed out by several authors as fast and clean, since it does not leave any residues in the extract, improves extract quality, productivity, yield and process selectivity [19,20]. Currently, this method is applied to prepare extracts for the phyto-pharmaceutical, cosmetic, and liqueur industries [20]. Another green technique with growing relevance is the microwave-assisted extraction (MAE). It presents short extraction cycles, uses reduced solvent amounts, provides high extraction rates, combined with lower costs $[21,22]$. UAE and MAE are currently amongst the foremost green techniques for accelerating extraction processes [20].

The effectiveness of these techniques depends on several variables and operating conditions and therefore, should not be generalized to any matrix due to the existing variability in composition. Consequently, it is necessary to select and optimize the extraction conditions depending on the used matrix, with the aim to ensure maximum yields with minimal time, solvent and energy [22,23]. One way to accomplish the optimization of any system is by measuring, independently, the influence of each variable when all the other ones are fixed. However, this type of approach does not provide the optimal operating conditions neither the interactions between variables. In this context, the application of mathematical models such as the response surface methodology (RSM) are gaining importance among the scientific community [22]. Based on an experimental design, the RSM analysis allows the simultaneous optimization of the variables taking into account complex interactions between them, supporting the prediction of the responses and their maximization [24,25].

In this study, the responses of the extraction performance were expressed in terms of RA extraction yield per $g$ of dry weight ( $\mathrm{mg}$ $\mathrm{RA} / \mathrm{g}$ of plant dw), purity of RA in the extracted residue - R (mg RA/ $\mathrm{g} R$ ) and extracted residue quantity ( $\mathrm{g}$ of $\mathrm{R} / \mathrm{g}$ of plant $\mathrm{dw}$ ). Therefore, the aim of the present study was to maximize the RA extraction yield from $M$. officinalis, in order to be considered its use in food, pharmaceutical and cosmetic industries. With this purpose, different extraction techniques (HAE, UAE and MAE) were studied and compared. From this study, it was expected to achieve the following targets: (1) optimize the primary variable conditions for RA extraction from $M$. officinalis maximizing the response criteria used; and (2) develop a consistent process in a pre-industrial form for contributing the understanding the potential of RA for industrial applications.

\section{Material and methods}

\subsection{Samples}

Melissa officinalis L dry leaves were provided by the company Pragmático Aroma Lda. ("Mais Ervas") based in Trás-os-Montes, Portugal. The samples were reduced to powder ( $\sim 20$ mesh). The obtained powder was mixed to guarantee the sample homogeneity and stored in a desiccator at room temperature $\left(\sim 25^{\circ} \mathrm{C}\right)$, protected from light, until further analysis.

\subsection{Standards and reagents}

Formic acid, HPLC grade ethanol and acetonitrile were from Fisher Scientific (Lisbon, Portugal). Rosmarinic acid standard was purchased from Extrasynthèse (Genay, France). Water was treated in Milli-Q water purification system (TGI Pure Water Systems, Greenville, SC, USA).

\subsection{Response format values for the results presentation}

The results were expressed in two response $(Y)$ format values: $Y_{1}$, in mg of RA per $g$ of plant dry weight material (mg RA/g plant $\mathrm{dw}$ ), which was specifically used to analyse the RA extraction yields; and $Y_{2}$, in $\mathrm{mg}$ of RA obtained in the extracted residue (mg $\mathrm{RA} / \mathrm{g} \mathrm{R}$ ), which was specifically used to evaluate the RA purity in the extracts. Both responses were equally analysed, but more considerations regarding the first one (mg RA/g plant $\mathrm{dw}$ ) were taken in the results presentation because, it would be the guiding response in terms of optimization or industrial transference. Note, that by dividing those responses $Y_{1} / Y_{2}$, it was obtained obtain $g$ of $\mathrm{R} / \mathrm{g}$ plant dw that provides the information regarding the extracted residue quantity.

\subsection{Description of the extraction techniques and used variables}

The relevant variables, and the selection of appropriate tested ranges, for each one of the studied extraction techniques, were obtained based on the combination of single variable preliminary experiments, on previous extractions studies performed at our laboratory and on bibliographic surveys. A detailed description of the study ranges for the selected variables (their definition can be consulted below in the respective points), used in the RSM design, is displayed in Table A1 (Supplemental material section). The solid/solvent ratio was kept constant $(30 \mathrm{~g} / \mathrm{L})$ for all techniques. The used solvent was an ethanol/water mixture characterized in terms of ethanol content $(\%, w / w)$.

\subsubsection{Heat-assisted extraction (HAE)}

The samples of dry powdered leaves $(600 \mathrm{mg}$ ) were placed in a beaker with $20 \mathrm{~mL}$ of solvent. The beaker was then placed in a thermostatic water bath under continuous electro-magnetic stirring for the required time. The variables and ranges tested were: time ( $t$ or $X_{1}, 30$ to $150 \mathrm{~min}$ ), temperature ( $T$ or $X_{2}, 30$ to $90{ }^{\circ} \mathrm{C}$ ) and ethanol solvent proportion ( $S$ or $X_{3}, 0$ to $100 \%$ ).

\subsubsection{Microwave-assisted extraction (MAE)}

MAE process was performed using a Biotage Initiator Microwave (Biotage ${ }^{\circledR}$ Initiator+, Uppsala, Sweden) using closed vessels. The samples of dried powdered leaves $(300 \mathrm{mg}$ ) were extracted with $10 \mathrm{~mL}$ of solvent. In enclosed microwave systems, the pressure and $T$ are correlated and the applied power is linked to the needed $t$ to reach the selected $T$ or pressure. In consequence, $T$ was selected as the main variable and the microwave power was set to $400 \mathrm{~W}$. Under the selected conditions, the needed $t$ to reach 
the selected $T$ was always less than $20 \mathrm{~s}$ thus guaranteeing a fast heating process (this time interval can be neglected considering the studied extraction time range). Therefore, the final variables and ranges tested were $t\left(X_{1}, 3\right.$ to $\left.45 \mathrm{~min}\right), T\left(X_{2}, 60\right.$ to $\left.180^{\circ} \mathrm{C}\right)$ and $S\left(X_{3}, 0\right.$ to $\left.100 \%\right)$.

\subsubsection{Ultrasound-assisted extraction (UAE)}

The UAE was carried out using an ultrasonic probe device (QSonica sonicators, model CL-334, Newtown, CT, USA). The samples of dried powdered leaves $(1.5 \mathrm{~g})$ were extracted with $50 \mathrm{~mL}$ using different times ( $t$ or $X_{1}, 3$ to $45 \mathrm{~min}$ ), ultrasound power ranges ( $P$ or $X_{2}, 100$ to $500 \mathrm{~W}$ ) and ethanol content ( $S$ or $X_{3}, 0$ to $100 \%$ ), while temperature was controlled with ice bath in order to be below $30-35^{\circ} \mathrm{C}$.

\subsubsection{Chemical characterization}

The extracts were filtered through a $0.22 \mu \mathrm{m}$ nylon filter and submitted to LC-DAD analysis. The chromatographic data were acquired from Dionex Ultimate 3000 UPLC (Thermo Scientific, San Jose, CA, USA), as previously described [26]. Detection was carried out using a DAD detector ( 280 and $370 \mathrm{~nm}$, as preferred wavelengths) and quantification was performed using a calibration curve with rosmarinic acid, constructed based on its UV signal. The results were expressed in $\mathrm{mg} \mathrm{RA} / \mathrm{g}$ plant $\mathrm{dw}$ and in $\mathrm{mg} \mathrm{RA} / \mathrm{g} \mathrm{R}$.

\subsection{Experimental design, model analysis and statistical evaluation}

\subsubsection{Experimental design}

The study of the impact of all the defined independent variables was carried out using one-factor-at-a-time, to pick the most influential one, and to determine the initial range of the processing variables. Through the analysis of these experimental results (data not shown), $X_{1}$ (time in $\mathrm{min}$ ), $X_{2}$ (temperature in ${ }^{\circ} \mathrm{C}$ ) and $X_{3}$ (ethanol proportion in \%) were chosen as variables for the RSM design. Therefore, the combined effect of these three variables were studied using a circumscribed central composite design (CCCD) using five levels for each one [27]. Thus, this design produces 20 response combinations, six of which are replicas at central point of the experiment and the others are independent experimental points built around the centre as a sphere. The centre point is presumed to be close to the optimum position for the response, so it is repeated to maximize the prediction [28]. In order to minimize the unpredictable effects in the observed responses, experimental runs were random. The mathematical expressions used to calculate the design distribution, code and decode the tested variables can be found in detail in the supplemental section and in Table A1. Once the optimal conditions $\left(X_{1}, X_{2}\right.$ and $\left.X_{3}\right)$ were found, the following natural optimization step is to describe the pattern of the solid/liquid ratio $\left(S / L\right.$ or $X_{4}$, expressed in $\left.g / L\right)$ in view of an industrial process application.

\subsubsection{Mathematical model}

The response surface models were fitted by means of leastsquares calculation using the following second-order polynomial equation:

$Y=b_{0}+\sum_{i=1}^{n} b_{i} X_{i}+\sum_{\substack{i=1 \\ j>i}}^{n-1} \sum_{j=2}^{n} b_{i j} X_{i} X_{j}+\sum_{i=1}^{n} b_{i i} X_{i}^{2}$

where $Y$ is the dependent variable (response variable) to be modelled, $X_{i}$ and $X_{j}$ define the independent variables, $b_{0}$ is the constant coefficient, $b_{i}$ is the coefficient of linear effect, $b_{i j}$ is the coefficient of interaction effect, $b_{i i}$ the coefficients of quadratic effect and $n$ is the number of variables. As responses, the three format values, $Y_{1}, \mathrm{mg}$ RA/g plant dw; $Y_{2}$, mg RA/g R; and $Y_{1} / Y_{2}, g$ R/g plant dw, were used.
2.5.3. Procedure to optimize the variables to a maximum response

For optimization of RA extraction, a maximized process of the model produced responses was achieved, using a simple method tool to solve non-linear problems [29,30]. Limitations were made to the variable coded values to avoid unnatural conditions (i.e., times lower than 0 ).

\subsection{Dose-response analysis of the solid to liquid ratio}

At the optimized best conditions of time $\left(X_{1}, t\right)$, temperature or ultrasound power $\left(X_{2}, T\right.$ or $\left.P\right)$ and ethanol solvent proportion $\left(X_{3}, S\right)$ a dose-response analysis of the solid to liquid ratio $\left(X_{4}, S / L\right.$ ratio $)$ was performed to describe its behaviour. To depict the response effect as function of the variation of the $S / L$ ratio the Weibull (W) equation [31] was used with some modifications to fit the purposes as follow:

$W(S / L)=K\left\{1-\exp \left[-\ln 2(S / L / m)^{a}\right]\right\}$

where $K$ is the maximum extraction value (response criteria units, i.e. if $Y_{1}$ the units would be $\mathrm{mg} \mathrm{RA} / \mathrm{g}$ plant $\left.\mathrm{dw}\right), m$ ( $S / L$ units, in this case $g$ plant $\mathrm{dw} / \mathrm{L}$ ) the dose required for $50 \%$ of the maximum extraction value $(K)$ and $a$ shape parameter related to the maximum slope of the response. The rate of the process parameter $(v$, i.e. if assessing the $Y_{1}$ response criterion the units would be $\mathrm{mg} \mathrm{RA} / \mathrm{g}$ plant dw per $g$ plant $d w / L$ ) can be obtained by using the parametric values of Eq. (2) as follows:

$v=\frac{K \alpha}{m}(\ln 2)^{1 / a} G^{G} \exp (-G) ;$ where $G=\frac{a-1}{a}$

The parameter $v$ provides the information related to the decreasing average value of the extraction as function of the increase of the $S / L$ variable. Therefore, the three parametric values of $K, m$ and $v$ can be used to assess the $S / L$ trends.

\subsection{Numerical methods, statistical analysis and graphical illustrations}

The statistical analysis and fitting of the experimental results were carried out according to the equations for the responses obtained using a Microsoft Excel spreadsheet in three phases:

(1) Coefficients measurement was achieved using the nonlinear least-square (quasi-Newton) method provided by the macro Solver in Microsoft Excel, by minimization of the sum of quadratic differences between observed and modelpredicted values [32].

(2) Coefficients significance was obtained via 'SolverAid' [32] to determine the parametric confidence intervals. The terms that were not statistically significant $(p>0.05)$ were dropped to simplify the model.

(3) Model reliability was confirmed by applying the following standards: (a) the Fisher F-test $(\alpha=0.05)$ to determine the consistency of the constructed models to describe the obtained data [33]; (b) the 'SolverStat' macro to make assessment of parameter and model prediction uncertainties [34]; (c) $R^{2}$ to explain the proportion variability of the dependent variable obtained by the model.

\section{Results and discussion}

3.1. Preliminary experiments to select the relevant variables and instrumental parameters to centre their experimental domain before the RSM application

Although there are scientific documents dealing with RA extraction from natural matrices $[10,17,35]$, no complete studies could be found describing the conditions of RA extraction from $M$. officinalis 
leaves and the effects of the main process variables of conventional and alternative extraction techniques, as well as the comparison between them. In general, the leaves of Rosmarinus officinalis are the most studied plant material for the extraction of RA. However, due to composition variability associated to natural sources, the conditions of $R$. officinalis cannot be directly extrapolated to be used with M. officinalis. Consequently, to find the optimal conditions and choose a suitable technique able to maximize RA extraction from $M$. officinalis, independent studies are necessary.

To define the conditions that maximize RA extraction from $M$. officinalis, it is necessary to understand how the relevant process variables affect the performance of different techniques (HAE, $\mathrm{UAE}$ and MAE). These variables can be divided into non-intrinsic factors (such as $S$ and $S / L$ ) and intrinsic factors ( $t$ and $T$ for the HAE and MAE systems, and $t$ and $P$ for the UAE system). Preliminary tests to evaluate these variables, and to determine their experimental domain for a RSM design, were conducted using one-factor-at-the-time (keeping others at a constant value). Additionally, a literature survey was carried out focusing on studies involving the extraction of RA from $M$. officinalis using similar processes.

Regarding the intrinsic factors of HAE, UAE and MAE, although worthy conclusions can be derived from the consulted bibliographic material $[10,17,35]$, results may be highly dependent on variations not directly foreseen in these studies. Thus, to optimize the response criteria the following ranges for the intrinsic factors were used: for $\operatorname{HAE} t(30-150 \mathrm{~min})$ and $T\left(30-90^{\circ} \mathrm{C}\right)$; for MAE $t$ (3-45 min) and $T\left(60-180^{\circ} \mathrm{C}\right)$; and for UAE $t(3-45 \mathrm{~min})$ and $P$ (100-500 W).

Therefore, in all extracting systems, the non-intrinsic variables and ranges were selected as follows:

(1) The solvent type and composition are key factors for the successful extraction of the desired compounds. Due to the RA chemical structure, the use of different water-based solvent mixtures are generally used as the extraction solvent, where the combination of water with different contents of methanol, ethanol or acetone are applied [10,35,36]. Considering the principles of green chemistry, binary mixtures of ethanol with water were selected as the extraction solvent. In all systems, the ethanol content was tested from 0 to $100 \%$ and confirmed as impacting significantly the RA extraction yield and, therefore, selected in the appropriate range.

(2) Regarding the $S / L$ factor, a broad range was tested, finding that lower values lead to an enhanced extraction yield, but also contribute to a significant waste of solvent. A higher $S / L$ will result in lower extraction yields but in a better rationalization of raw materials consumption. Although the differences were significant, it was initially discarded as a variable to be optimized at the RSM study, and the value of $30 \mathrm{~g} / \mathrm{L}$ was selected to be used in this study with all the tested extraction techniques. Once the optimal conditions for each technique were defined in terms of the other studied variables, the study proceeded with the analysis of the $S /$ $L$ condition by a dose-response analysis.

In conclusion, the efficiency of the HAE, UAE and MAE processes for RA extraction from $M$. officinalis was performed by the application of a RSM of three variables in a CCCD (five level values of each factor). The optimization of RA extraction yield in HAE, UAE and MAE with the RSM provides a strong solution that minimizes the errors with a short number of experimental trials. As stated before [37], the multivariable fitting decreases the number of parameters needed to analyse the response leading to better estimations and reducing their interval of confidence. A detailed description of all the tested values for each one of the used techniques can be found in Table A1 (supplemental material section). In Fig. A1, a comprehensive summary of the different steps carried out for optimizing is presented.

\subsection{Mathematical models derived from the RSM for a CCCD with three variables and statistical assessment}

The results obtained by the statistical CCCD are shown in the first part of Table 1 for each one of the employed extraction techniques. By fitting the second-order polynomial model of Eq. (1) to the obtained responses using nonlinear least-squares estimations, the parametric values are obtained and presented in Table 2. Therefore, the resulting models for each assessed extraction technique are the following:

For the response format $Y_{1}$ (mg RA/g plant dw):

$$
\text { for HAE : } \begin{aligned}
& Y_{M E}^{Y_{1}} \\
= & 55.5+0.57 t+3.2 T-9.6 S-0.62 t^{2}-1.47 T^{2} \\
& -14.3 S^{2}-3.1 T S
\end{aligned}
$$

for UAE : $Y_{U A E}^{Y_{1}}$

$$
=141.7+4.4 t+1.8 T-18.4 S-40.8 S^{2}-8.9 T S
$$

for MAE : $Y_{M A E}^{Y_{1}}$

$$
=0.39+0.02 t+0.02 T-0.08 S-0.04 S^{2}+0.01 T S
$$

For the response format $Y_{2}$ (mg RA/g R):

$$
\text { for } \begin{aligned}
\mathrm{HAE}: & Y_{M E}^{Y_{2}} \\
= & 79.3+8.7 t+10.1 T-6.9 S-3.1 t^{2}-3.4 T^{2} \\
& -19.8 S^{2}+7.6 t T+3.9 t S+2.5 T S
\end{aligned}
$$

for UAE : $Y_{U A E}^{Y_{2}}=145.8+17.1 t+17.2 T+9.4 t^{2}-25.1 S^{2}$

$$
+23.5 t T+8.5 t S
$$

for MAE : $Y_{M A E}^{Y_{2}}=0.55-0.10 S-0.05 t^{2}-0.04 T^{2}-0.07 S^{2}$

$$
-0.04 t T-0.02 t S
$$

For the response format $Y_{1} / Y_{2}$ (g R/g plant $\mathrm{dw}$ ):

for HAE : $Y_{M E}^{Y_{1} / Y_{2}}=44.9+0.92 t-3.6 T-9.1 S-1.1 t^{2}-5.3 T^{2}-5.5 S^{2}$

$$
\begin{aligned}
& \text { for } \begin{aligned}
\mathrm{UAE}: & Y_{U A E}^{Y_{1} / Y_{2}}=192.2-27.0 T-10.7 S-9.4 t^{2}-26.6 T^{2}-6.7 S^{2} \\
\text { for MAE }: & Y_{M A E}^{Y_{1} / Y_{2}} \\
= & 0.23+0.01 t+0.02 T-0.04 S-0.01 T^{2}-0.02 S^{2}
\end{aligned}
\end{aligned}
$$

Those coefficients, which showed confidence interval values $(\alpha=0.05)$ higher than the parameter value, were consider as non-significant (ns) and were not used for the model development. Equations from (4) to (12) translate the response patterns for the three response criteria formats $\left(Y_{1}\right.$ in $\mathrm{mg} \mathrm{RA} / \mathrm{g}$ plant $\mathrm{dw}, Y_{2}$ in $\mathrm{mg}$ $\mathrm{RA} / \mathrm{g} \mathrm{R}$ and $Y_{1} / Y_{2}$ in $\mathrm{g} \mathrm{R} / \mathrm{g}$ plant dw) showing a relatively high complexity of the possible sceneries.

For the HAE, UAE and MAE techniques and for each response criteria, the linear and quadratic effects are found to play an important and significant role, while regarding the interactive effects, no significant effects were found for the MAE system.

Figs. 1, A2 and A3 (supplementary material) show the extraction results for the three response criteria formats ( $Y_{1}$ in $\mathrm{mg} \mathrm{RA} / \mathrm{g}$ plant dw, $Y_{2}$ in mg RA/g R and $Y_{1} / Y_{2}$ in $\mathrm{g}$ R/g plant dw), respectively. The figures are divided in three columns, each one shows the 
Table 1

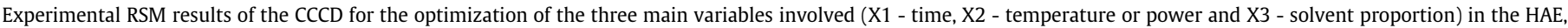

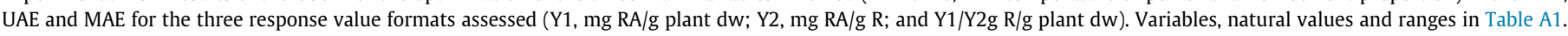
Three replicates were performed for each condition for each technique.

\begin{tabular}{|c|c|c|c|c|c|c|c|c|c|c|c|}
\hline \multirow{2}{*}{\multicolumn{3}{|c|}{ Variable coded values }} & \multicolumn{9}{|c|}{ Experimental responses } \\
\hline & & & \multicolumn{3}{|c|}{ Heat-assisted Extraction (HAE) } & \multicolumn{3}{|c|}{ Ultrasound (UAE) } & \multicolumn{3}{|c|}{ Microwave (MAE) } \\
\hline$X_{1}$ & $X_{2}$ & $X_{3}$ & $Y_{1}$ & $Y_{2}$ & $Y_{1} / Y_{2}$ & $Y_{1}$ & $Y_{2}$ & $Y_{1} / Y_{2}$ & $Y_{1}$ & $Y_{2}$ & $Y_{1} / Y_{2}$ \\
\hline-1 & -1 & -1 & 42.70 & 102.07 & 0.418 & 48.90 & 112.41 & 0.435 & 40.06 & 161.54 & 0.248 \\
\hline 1 & -1 & -1 & 42.81 & 109.49 & 0.391 & 44.24 & 88.13 & 0.502 & 43.49 & 181.73 & 0.239 \\
\hline-1 & 1 & -1 & 54.65 & 128.50 & 0.425 & 56.90 & 120.38 & 0.473 & 41.47 & 151.73 & 0.273 \\
\hline 1 & 1 & -1 & 58.54 & 136.13 & 0.430 & 74.34 & 167.43 & 0.444 & 33.94 & 124.17 & 0.273 \\
\hline-1 & -1 & 1 & 23.31 & 81.79 & 0.285 & 28.08 & 97.51 & 0.288 & 21.51 & 124.58 & 0.173 \\
\hline 1 & -1 & 1 & 25.53 & 92.38 & 0.276 & 30.75 & 84.78 & 0.363 & 19.83 & 107.78 & 0.184 \\
\hline-1 & 1 & 1 & 25.44 & 78.44 & 0.324 & 37.76 & 92.55 & 0.408 & 22.84 & 105.10 & 0.217 \\
\hline 1 & 1 & 1 & 25.86 & 77.27 & 0.335 & 79.15 & 196.51 & 0.231 & 22.43 & 98.11 & 0.229 \\
\hline-1.68 & 0 & 0 & 55.81 & 142.01 & 0.393 & 56.57 & 151.26 & 0.374 & 39.27 & 173.75 & 0.226 \\
\hline 1.68 & 0 & 0 & 56.50 & 140.09 & 0.403 & 93.64 & 222.23 & 0.421 & 50.45 & 207.31 & 0.243 \\
\hline 0 & -1.68 & 0 & 50.46 & 149.74 & 0.337 & 61.74 & 150.34 & 0.411 & 46.43 & 222.52 & 0.209 \\
\hline 0 & 1.68 & 0 & 57.07 & 143.52 & 0.398 & 86.96 & 174.80 & 0.432 & 19.63 & 60.97 & 0.322 \\
\hline 0 & 0 & -1.68 & 27.24 & 57.59 & 0.473 & 41.46 & 73.17 & 0.567 & 47.57 & 186.79 & 0.255 \\
\hline 0 & 0 & 1.68 & 7.67 & 94.69 & 0.081 & 14.35 & 105.52 & 0.136 & 17.02 & 209.24 & 0.081 \\
\hline 0 & 0 & 0 & 52.45 & 133.12 & 0.394 & 78.88 & 146.15 & 0.579 & 42.59 & 178.46 & 0.239 \\
\hline 0 & 0 & 0 & 56.62 & 143.70 & 0.374 & 81.31 & 150.20 & 0.541 & 47.67 & 203.13 & 0.235 \\
\hline 0 & 0 & 0 & 56.41 & 143.16 & 0.345 & 77.50 & 144.86 & 0.575 & 48.01 & 202.85 & 0.237 \\
\hline 0 & 0 & 0 & 57.16 & 145.07 & 0.384 & 83.22 & 150.03 & 0.555 & 44.50 & 191.33 & 0.228 \\
\hline 0 & 0 & 0 & 53.86 & 136.69 & 0.376 & 75.93 & 144.54 & 0.525 & 49.33 & 212.03 & 0.233 \\
\hline 0 & 0 & 0 & 55.64 & 141.22 & 0.391 & 77.91 & 149.63 & 0.521 & 46.74 & 196.94 & 0.237 \\
\hline
\end{tabular}

results for each of the tested techniques. Additionally, each column is divided into two sections ( $\mathrm{A}$ and $\mathrm{B}$ ). The section $\mathrm{A}$ shows the $3 \mathrm{D}$ surface plots for the three possible variable combinations produced by Eqs. (4)(12). The binary action between variables is presented when the excluded variable is positioned at the centre of the experimental domain (see Table A1, supplementary material). Subsection B illustrates the capability to predict the obtained results and the residual distribution as a function of each one of the considered variables.

In almost all combinatory 3D responses of Fig. 1, A2 and A3 (supplementary material), the amount of extracted material increases to an optimum value and then decreases as a function of each of the assessed independent variables. Therefore, in almost all combinations, an absolute optimum can be found at one single point along with the response, allowing computing the conditions that lead to the absolute maximum.

In statistical terms, the tests used to assess the competence of the models showed that the non-significant parameters of both RSM approaches (Table 2) did not improve the reached solution and, in contrast, all significant parameters were highly consistent $(\mathrm{p}<0.01)$. This was also verified by the achieved high $\mathrm{R}^{2}$ and $\mathrm{R}_{\mathrm{adj}}^{2}$ values, indicating the percentage of variability explained by the model. The distribution of the residuals presented in Figs. 1, A2 and A3 (supplementary material) was arbitrarily around zero and no group of values or autocorrelations were observed. Additionally, the agreement between the experimental and predicted values implies an acceptable explanation of the results obtained by the independent variables used. Therefore, the models developed in Eqs. (4)(12) are completely functional and adequate to be used for prediction and process optimization.

\subsection{Numerical optimal conditions that maximize the extraction and experimental verification of predictive models}

Two types of optimal conditions are produced: (1) the absolute (or relative) optimal conditions, which accounts for the optimal value for specific response criterion; and (2) the global optimal conditions that provides the optimal global value for a group of response criteria.
By applying a simple procedure inserting restrictions to the experimental ranges, the optimal absolute or relative (marked as (*) when the optimal value may be outside of the experimental range studied) conditions that maximize the responses criteria are achieved (Table 3 ).

- For the HAE system: for response criteria $Y_{1}$ (mg RA/g plant dw) that correspond to the RA extraction yield, the optimal conditions were found to be $106.2 \pm 5.1 \mathrm{~min}, 88.0 \pm 6.1^{\circ} \mathrm{C}$ and $34.8 \pm 6.1 \%$ of ethanol, producing a maximum response value of $60.4 \pm 2.7 \mathrm{mg} \mathrm{RA} / \mathrm{g}$ plant $\mathrm{dw}$; for response criteria $Y_{2}(\mathrm{mg}$ $\mathrm{RA} / \mathrm{g} \mathrm{R}$ ) that analysed the RA purity in the extracted residue the optimal conditions were found to be $90.0 \pm 9.1 \mathrm{~min},(*)$ $90.0 \pm 6.1^{\circ} \mathrm{C}$ and $37.8 \pm 3.7 \%$ of ethanol, producing a maximum response value of $161.6 \pm 7.2 \mathrm{mg} \mathrm{RA} / \mathrm{g} \mathrm{R}$; and for response criteria $Y_{1} / Y_{2}(\mathrm{~g} \mathrm{R} / \mathrm{g}$ plant $\mathrm{dw}$ ) that analysed the yield of the extracted residue the optimal conditions were found to be $(*)$ $150.0 \pm 8.4 \mathrm{~min},(*) 90.0 \pm 6.2^{\circ} \mathrm{C}$ and $22.5 \pm 2.1 \%$ of ethanol, producing a maximum response value of $0.493 \pm 0.06 \mathrm{~g} \mathrm{R} / \mathrm{g}$ plant dw.

- For UAE response: for $Y_{1}$, the optimal conditions were found to be (*) $45.0 \pm 3.6 \mathrm{~min},(*) 500.0 \pm 5.5 \mathrm{~W}$ and $52.9 \pm 2.2 \%$ of ethanol, producing $97.6 \pm 8.4 \mathrm{mg} \mathrm{RA} / \mathrm{g}$ plant $\mathrm{dw}$; for $Y_{2}$, conditions were at $(*) 45.0 \pm 3.2 \mathrm{~min},(*) 500.0 \pm 4.1 \mathrm{~W}$ and $58.5 \pm 5.1 \%$ of ethanol, producing $298.3 \pm 9.3 \mathrm{mg} \mathrm{RA} / \mathrm{g} \mathrm{R}$; and for $Y_{1} / Y_{2}$, the optimal conditions were found to be $26.0 \pm 2.1 \mathrm{~min}$, $290.7 \pm 11.7 \mathrm{~W}$ and $28.5 \pm 3.2 \%$ of ethanol, producing $0.583 \pm 0.11 \mathrm{~g} \mathrm{R} / \mathrm{g}$ plant $\mathrm{dw}$.

- For MAE response: for $Y_{1}$, the optimal conditions were found to be $29.0 \pm 1.9 \mathrm{~min}, 108.2 \pm 4.9{ }^{\circ} \mathrm{C}$ and $25.9 \pm 1.1 \%$ of ethanol, producing $49.5 \pm 2.6 \mathrm{mg} \mathrm{RA} / \mathrm{g}$ plant $\mathrm{dw}$; for $Y_{2}$ the optimal conditions were found to be $24.0 \pm 2.2 \mathrm{~min}, 102.3 \pm 6.2{ }^{\circ} \mathrm{C}$ and $26.4 \pm 1.1 \%$ of ethanol, producing $203.3 \pm 1.2 \mathrm{mg} \mathrm{RA} / \mathrm{g} \mathrm{R}$; and for $Y_{1} / Y_{2}$ the optimal conditions were found to be $(*)$ $45.0 \pm 4.5 \mathrm{~min},(*) 178.8 \pm 9.1{ }^{\circ} \mathrm{C}$ and $24.3 \pm 7.1 \%$ of ethanol, producing $0.334 \pm 0.09 \mathrm{~g} \mathrm{R} / \mathrm{g}$ plant $\mathrm{dw}$.

Fig. 2 shows the optimized isolines projections for the combination of the three main variables involved $\left(X_{1}, X_{2}\right.$ and $\left.X_{3}\right)$ in the HAE, $\mathrm{UAE}$ and MAE of the three response value formats $\left(Y_{1}, \mathrm{mg} \mathrm{RA} / \mathrm{g}\right.$ 
Table 2

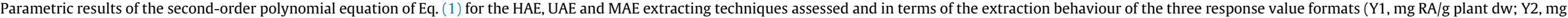

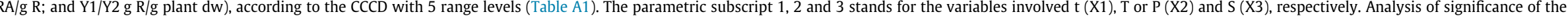
parameters $(\alpha=0.05)$ are presented in coded values. Additionally, the statistical information of the fitting procedure to the model is presented.

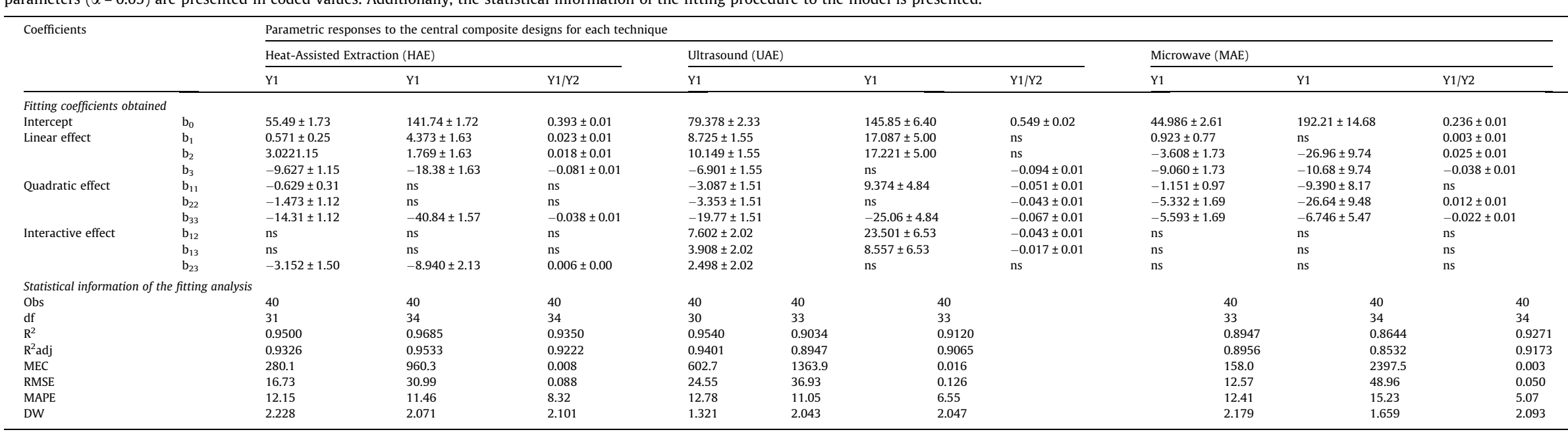

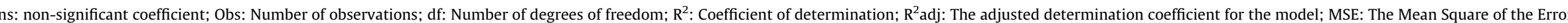
RMSE: The Root Mean Square of the Errors; MAPE: The Mean Absolute Percentage Error; and DW: The Durbin-Watson statistic. 

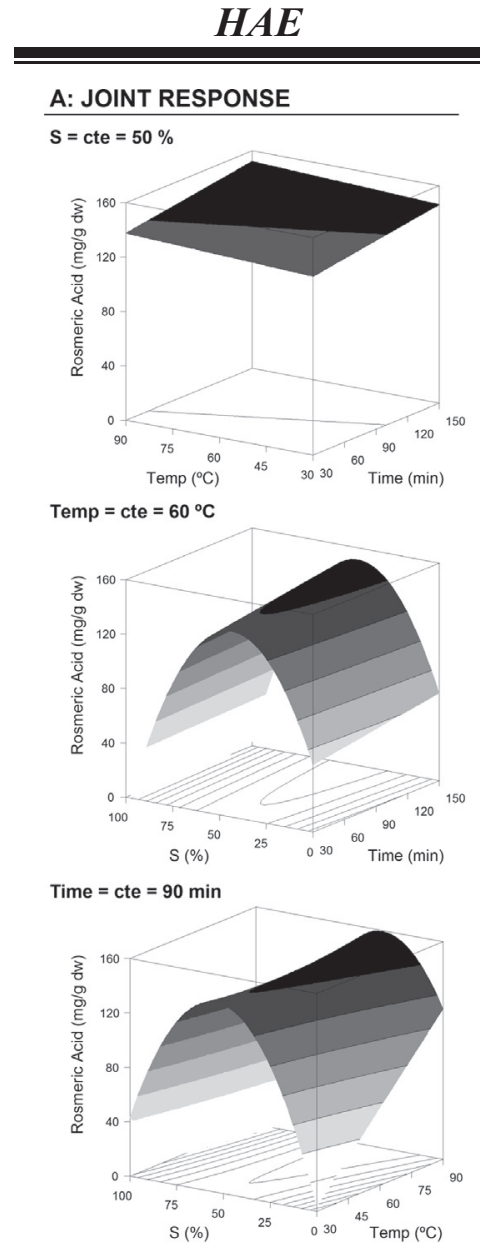

\section{B: ESTATISTICAL DISTRIBUTION}

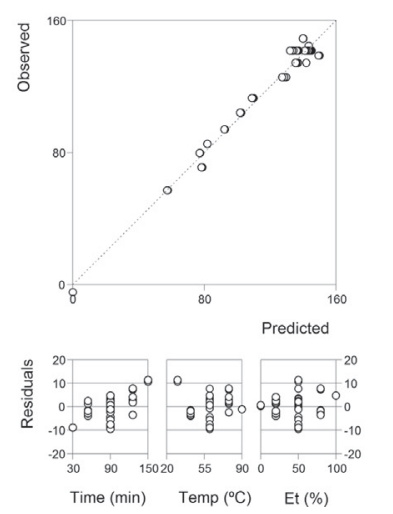

$\boldsymbol{U} A \boldsymbol{E}$
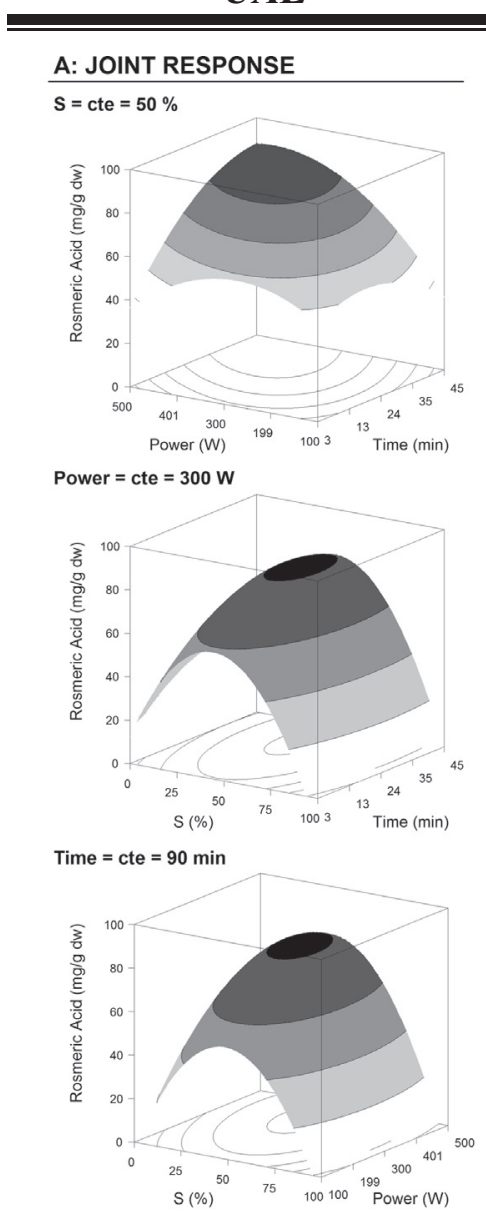

B: ESTATISTICAL DISTRIBUTION
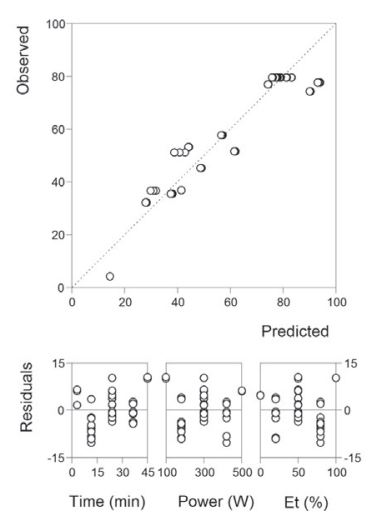

$M A E$
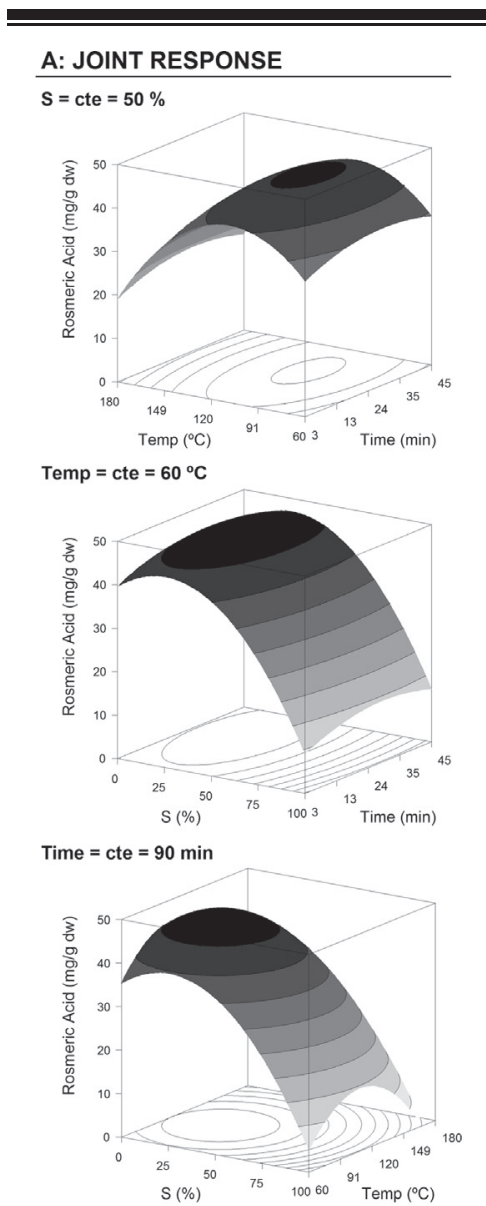

B: ESTATISTICAL DISTRIBUTION

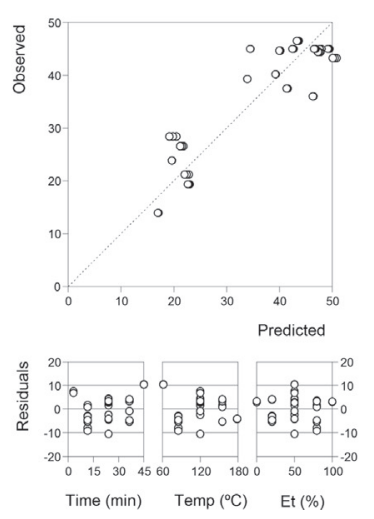

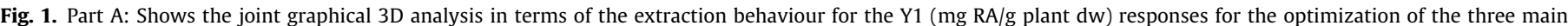

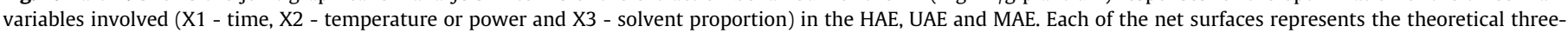

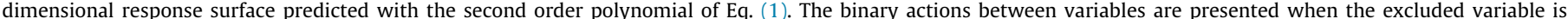

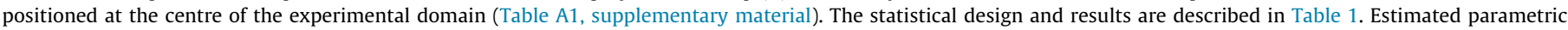

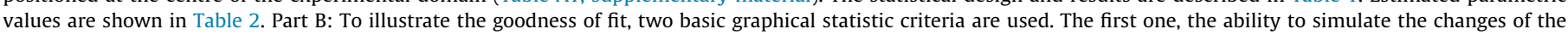

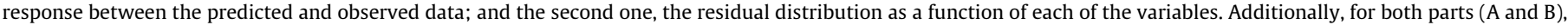
note all the differences in the axes scales.

plant dw; $Y_{2}, \mathrm{mg} \mathrm{RA} / \mathrm{g} \mathrm{R}$; and $Y_{1} / Y_{2}, \mathrm{~g} \mathrm{R} / \mathrm{g}$ plant dw) to describe visually the tendencies of each response and guide the selection of the most favourable conditions, taken into account simultaneously all responses. Each of the contour graphs represents the projection in $\mathrm{XY}$ plane of the theoretical three-dimensional response surface predicted with the second order polynomial of Eq. (1). The binary actions between variables are presented when the excluded variable is positioned at the individual optimum of the experimental domain (Table 3 ).

When combining, the information produced by the three responses criteria $\left(Y_{1}, Y_{2}\right.$ and $\left.Y_{1} / Y_{2}\right)$, the complete behaviour of each relevant variable influencing the responses is defined in global terms. The global optimizing results are presented in Table 3 and summarized below: 
Table 3

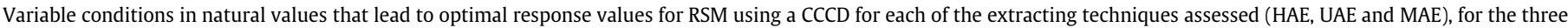
individual response value formats (Y1, mg RA/g plant dw; Y2, mg RA/g R; and Y1/Y2 g R/g plant dw) and for the global optimal conditions.

\begin{tabular}{|c|c|c|c|c|c|c|}
\hline \multirow[t]{2}{*}{ Criteria } & & \multicolumn{3}{|c|}{ Optimal variable conditions } & \multirow{2}{*}{\multicolumn{2}{|c|}{ Optimum response }} \\
\hline & & $\mathrm{X}_{1}: \mathrm{t}(\mathrm{min})$ & $\mathrm{X}_{2}: \mathrm{T}\left({ }^{\circ} \mathrm{C}\right)$ or $\mathrm{P}(\mathrm{W})$ & $\mathrm{X}_{3}: \mathrm{S}(\%)$ & & \\
\hline Heat-assisted extraction (HAE) & $\begin{array}{l}\mathrm{Y}_{1} \\
\mathrm{Y}_{2} \\
\mathrm{Y}_{1} / \mathrm{Y}_{2}\end{array}$ & $\begin{array}{l}106.2 \pm 5.1 \\
90.0 \pm 9.1 \\
150.0 \pm 8.4\end{array}$ & $\begin{array}{l}88.0 \pm 6.1 \\
90.0 \pm 6.1 \\
90.0 \pm 6.2\end{array}$ & $\begin{array}{l}34.8 \pm 6.1 \\
37.8 \pm 3.7 \\
22.5 \pm 2.1\end{array}$ & $\begin{array}{l}60.4 \pm 2.7 \\
161.6 \pm 7.2 \\
0.493 \pm 0.06\end{array}$ & $\begin{array}{l}\text { mg RA/g plant dw } \\
\text { mg RA/g R } \\
\text { g R/g plant dw }\end{array}$ \\
\hline Ultrasound (UAE) & $\begin{array}{l}\mathrm{Y}_{1} \\
\mathrm{Y}_{2} \\
\mathrm{Y}_{1} / \mathrm{Y}_{2}\end{array}$ & $\begin{array}{l}45.0 \pm 3.6 \\
45.0 \pm 3.2 \\
26.0 \pm 2.1\end{array}$ & $\begin{array}{l}500.0 \pm 5.5 \\
500.0 \pm 4.1 \\
290.7 \pm 11.7\end{array}$ & $\begin{array}{l}52.9 \pm 2.2 \\
58.5 \pm 5.1 \\
28.5 \pm 3.2\end{array}$ & $\begin{array}{l}97.6 \pm 8.4 \\
298.3 \pm 9.3 \\
0.583 \pm 0.11\end{array}$ & $\begin{array}{l}\text { mg RA/g plant dw } \\
\text { mg RA/g R } \\
\text { g R/g plant dw }\end{array}$ \\
\hline Microwave (MAE) & $\begin{array}{l}\mathrm{Y}_{1} \\
\mathrm{Y}_{2} \\
\mathrm{Y}_{1} / \mathrm{Y}_{2}\end{array}$ & $\begin{array}{l}29.0 \pm 1.9 \\
24.0 \pm 2.2 \\
45.0 \pm 4.5\end{array}$ & $\begin{array}{l}108.2 \pm 4.9 \\
102.3 \pm 6.2 \\
178.8 \pm 9.1\end{array}$ & $\begin{array}{l}25.9 \pm 1.1 \\
26.4 \pm 1.1 \\
24.3 \pm 7.1\end{array}$ & $\begin{array}{l}49.5 \pm 2.6 \\
203.3 \pm 1.2 \\
0.334 \pm 0.09\end{array}$ & $\begin{array}{l}\text { mg RA/g plant dw } \\
\text { mg RA/g R } \\
\text { g R/g plant dw }\end{array}$ \\
\hline Heat-assisted extraction (HAE) & $\begin{array}{l}\mathrm{Y}_{1} \\
\mathrm{Y}_{2} \\
\mathrm{Y}_{1} / \mathrm{Y}_{2}\end{array}$ & $106.2 \pm 5.1$ & $88.0 \pm 2.9$ & $34.5 \pm 1.6$ & $\begin{array}{l}59.4 \pm 2.2 \\
158.3 \pm 12.1 \\
0.487 \pm 0.04\end{array}$ & $\begin{array}{l}\text { mg RA/g plant dw } \\
\text { mg RA/g R } \\
\text { g R/g plant dw }\end{array}$ \\
\hline Ultrasound (UAE) & $\begin{array}{l}\mathrm{Y}_{1} \\
\mathrm{Y}_{2} \\
\mathrm{Y}_{1} / \mathrm{Y}_{2}\end{array}$ & $33.0 \pm 3.2$ & $371.7 \pm 19.3$ & $39.9 \pm 1.4$ & $\begin{array}{l}86.3 \pm 4.1 \\
178.5 \pm 13.2 \\
0.517 \pm 0.07\end{array}$ & $\begin{array}{l}\text { mg RA/g plant dw } \\
\text { mg RA/g R } \\
\text { g R/g plant dw }\end{array}$ \\
\hline Microwave (MAE) & $\begin{array}{l}\mathrm{Y}_{1} \\
\mathrm{Y}_{2} \\
\mathrm{Y}_{1} / \mathrm{Y}_{2}\end{array}$ & $26.5 \pm 2.1$ & $108.6 \pm 10.2$ & $25.5 \pm 0.9$ & $\begin{array}{l}49.4 \pm 2.3 \\
202.1 \pm 13.1 \\
0.246 \pm 0.03\end{array}$ & $\begin{array}{l}\text { mg RA/g plant dw } \\
\text { mg RA/g R } \\
\text { g R/g plant dw }\end{array}$ \\
\hline
\end{tabular}

\section{$H A E$}

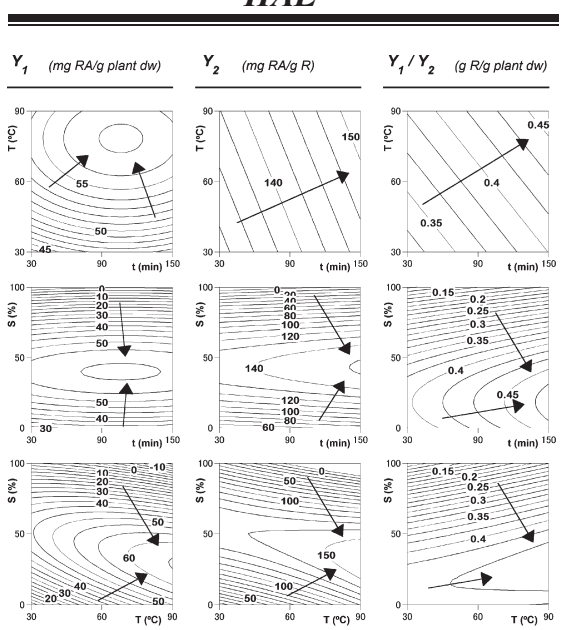

$U A E$

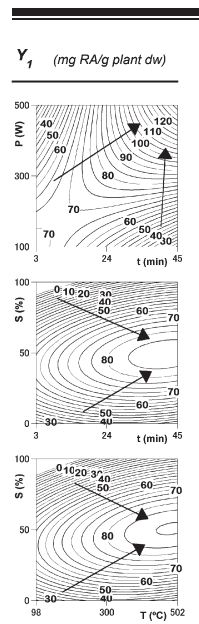

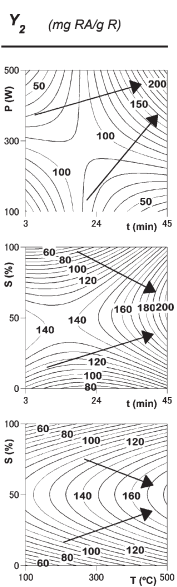
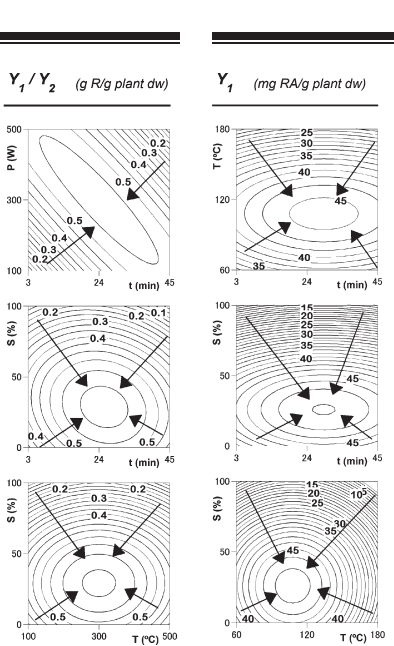

$M A E$
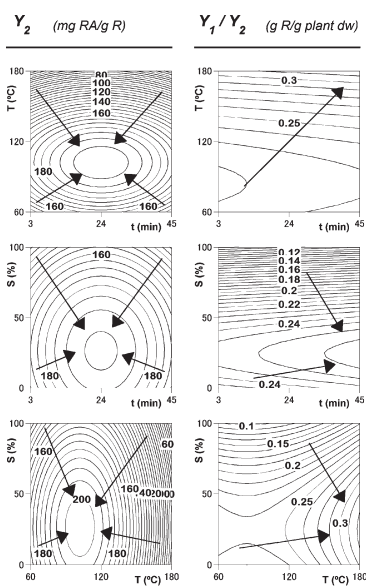

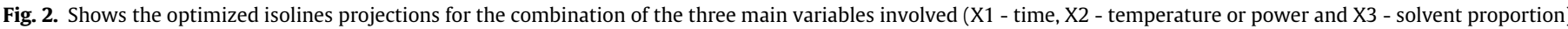

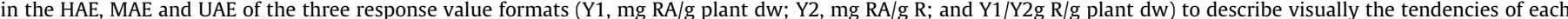

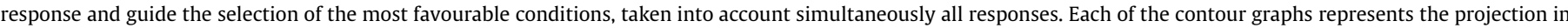

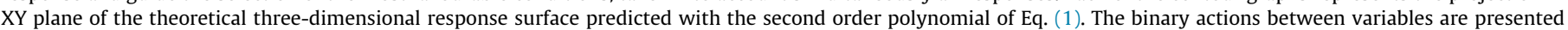

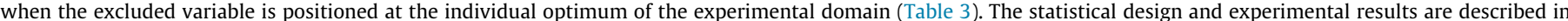
Table 1. Estimated parametric values are shown in Table 2.

- For the HAE system: the optimal global conditions were at $106.2 \pm 5.1 \mathrm{~min}, 88.0 \pm 2.9^{\circ} \mathrm{C}$ and $34.5 \pm 1.6 \%$ of ethanol, producing $59.4 \pm 2.2 \mathrm{mg} \mathrm{RA} / \mathrm{g}$ plant dw $\left(Y_{1}\right), 158.3 \pm 12.1 \mathrm{mg} \mathrm{RA} / \mathrm{g}$ $\mathrm{R}\left(Y_{2}\right)$ and $0.487 \pm 0.04 \mathrm{~g} \mathrm{R} / \mathrm{g}$ plant $\mathrm{dw}\left(Y_{1} / Y_{2}\right)$.

- For UAE response: the optimal global conditions were at $33.0 \pm 3.2 \mathrm{~min}, 371.7 \pm 19.3 \mathrm{~W}$ and $39.9 \pm 1.4 \%$ of ethanol, producing $86.3 \pm 4.1 \mathrm{mg} \mathrm{RA} / \mathrm{g}$ plant dw $\left(Y_{1}\right), 178.5 \pm 13.2 \mathrm{mg} \mathrm{RA} / \mathrm{g}$ $\mathrm{R}\left(Y_{2}\right)$ and $0.517 \pm 0.07 \mathrm{~g} \mathrm{R} / \mathrm{g}$ plant $\mathrm{dw}\left(Y_{1} / Y_{2}\right)$.

- For MAE response: the optimal global conditions were at $26.5 \pm 2.1 \mathrm{~min}, 108.6 \pm 10.2{ }^{\circ} \mathrm{C}$ and $25.5 \pm 0.9 \%$ of ethanol, producing $49.4 \pm 2.3 \mathrm{mg} \mathrm{RA} / \mathrm{g}$ plant dw $\left(Y_{1}\right), 202.1 \pm 13.1 \mathrm{mg} \mathrm{RA} / \mathrm{g}$ $\mathrm{R}\left(Y_{2}\right)$ and $0.246 \pm 0.03 \mathrm{~g} \mathrm{R} / \mathrm{g}$ plant $\mathrm{dw}\left(Y_{1} / Y_{2}\right)$.

For all techniques, the conditions that lead to the optimal values were experimentally tested in order to ensure the accuracy of the presented results. Fig. 3A, shows the summarized individual $2 \mathrm{D}$ responses as a function of the defined variables for HAE, UAE and MAE extraction techniques to guide the selection of the most favourable conditions. The line represents the variable response pattern when the others are located at the optimal values presented in the third part of Table 3 . The dots $(\odot)$ presented alongside the line highlight the location of the optimal value. Comparing the results of extraction efficiencies among the techniques, UAE gave significantly higher values, while HAE and MAE extraction generated lower values. Regarding the extraction time, MAE was the fastest extraction method while HAE was the longest.

\subsection{Dose-response analysis of the solid-to-liquid effect at the optimum conditions}

The studies on $S / L$ were performed at the global optimal conditions predicted by the polynomial models obtained for each extrac- 


\section{A: Illustration of the interaction between variables}
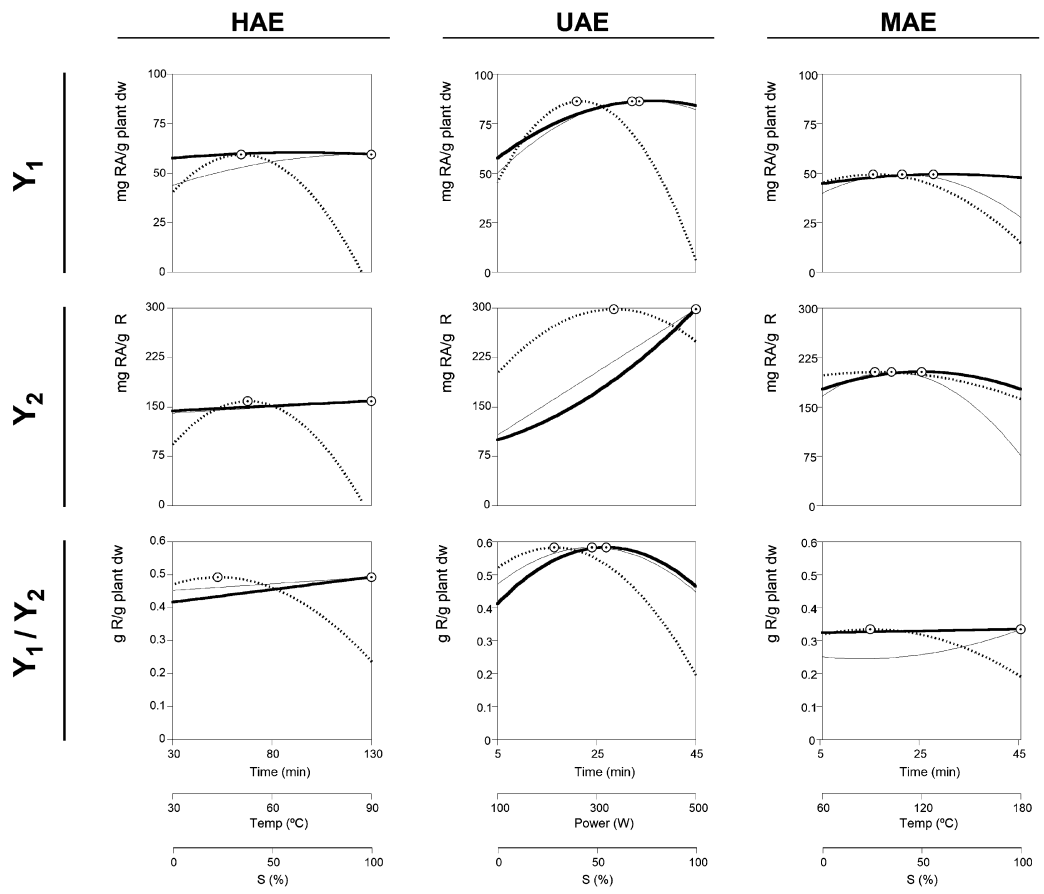

$-t(\min )$

$T\left({ }^{\circ} \mathrm{C}\right)$ or $P(\mathrm{~W})$

……. $S(\%)$

\section{B: Solid-to-liquid ratio patterns}

\section{B1: Experimental results}
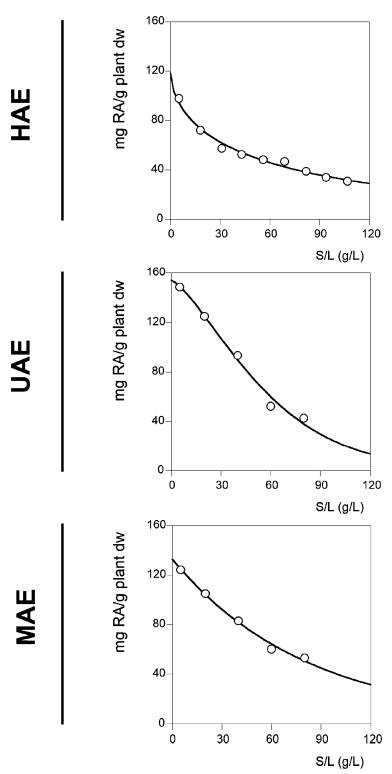

B2: Patterns of solid-to-liquid ratio

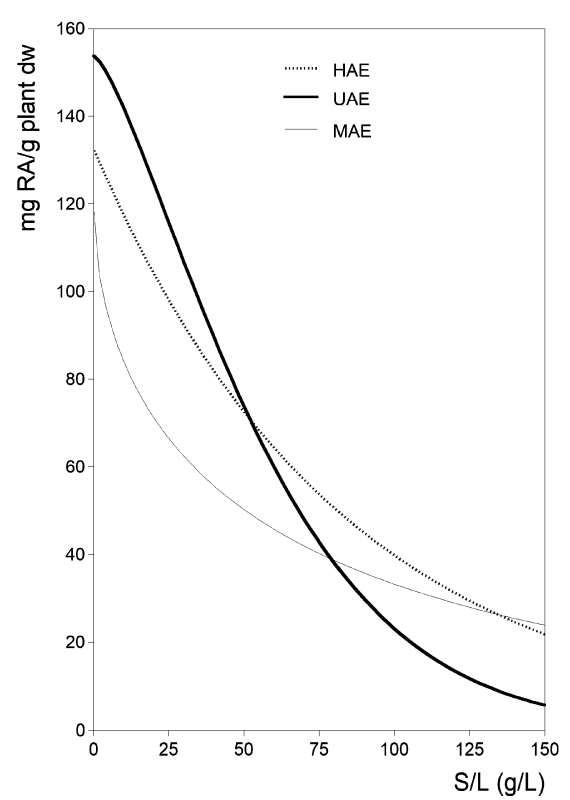

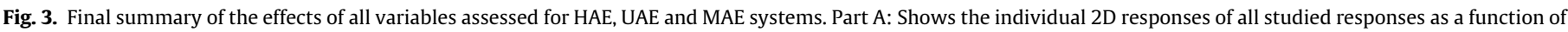

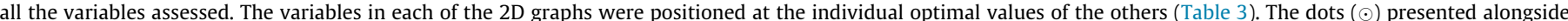

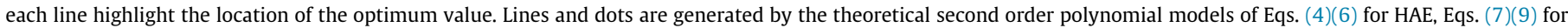

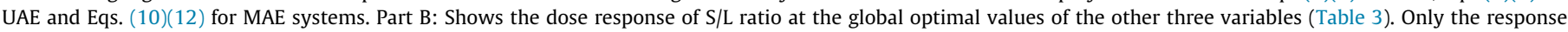

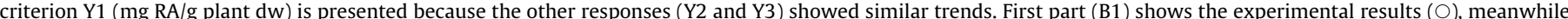

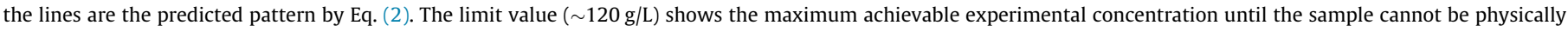
stirred at laboratory scale. Second part (B2) shows the dose-response trends for HAE, UAE and MAE jointly for comparison purposes. 
tion technique. Preliminary results indicated that the experimental limit value was proximal to $120 \mathrm{~g} / \mathrm{L}$. Therefore, the dose-response process of extraction was designed to verify the $S / L$ patterns between $5 \mathrm{~g} / \mathrm{L}$ until $100 \mathrm{~g} / \mathrm{L}$. The $S / L$ effect can be described by a simple non-linear relationship using Eq. (2). The effects of the $S / L$ dose-response for the HAE, UAE and MAE techniques are presented in Fig. 3B. Only the response criterion $Y_{1}$ (mg RA/g plant $\mathrm{dw})$ is presented because the other responses $\left(Y_{2}\right.$ and $\left.Y_{3}\right)$ showed similar trends. In all cases, the responses obtained through the HAE, UAE and MAE systems are consistent with the previous results. Fig. 3B1 shows the experimental results (dots) and model predictions of Eq. (2) (lines) obtained for each technique. The $S / L$ increase leads to a decrease in the extraction ability of the solvent; consequently, the extraction responses reach a maximum value at minimum values of $S / L$ and a minimum at higher values of $S / L$ (in our case $120 \mathrm{~g} / \mathrm{L}$ was the experimental limit achieved) and the respective losses are justified by parametric results derived from Eq. (2) and (3) in terms of the response criterion $Y_{1}$ (mg RA/g plant $\mathrm{dw})$ as follows.

- For the HAE system: the value of $K$ that accounts for the maximum yield extraction of RA was found to be $118.6 \pm 12.2 \mathrm{mg}$ $\mathrm{RA} / \mathrm{g}$ plant dw; the value of $m$ that accounts for the $S / L$ value that provides $50 \%$ of the parameter value $K$ (IC50) was found to be $34.4 \pm 4.7 \mathrm{~g}$ plant $\mathrm{dw} / \mathrm{L}$; the value of $v$ that provides the decreasing average rate of process was found to be $0.680 \pm 0.09 \mathrm{mg} \mathrm{RA} / \mathrm{g}$ plant dw per g plant $\mathrm{dw} / \mathrm{L}$; the coefficient of determination $\mathrm{R}^{2}$ achieved was 0.9834 ; and the dimensionless shape parameter $a$ was found to be $0.6 \pm 0.1$.

- For UAE response: $K=153.8 \pm 17.8 \mathrm{mg} \mathrm{RA} / \mathrm{g}$ plant $\mathrm{dw}$; $m=48.1 \pm 6.3 \mathrm{~g}$ plant $\mathrm{dw} / \mathrm{L} ; v=1.523 \pm 0.32 \mathrm{mg} \mathrm{RA} / \mathrm{g}$ plant $\mathrm{dw}$ per g plant dw/L; $\mathrm{R}^{2}=0.9886$; and $a=1.4 \pm 0.1$.

- For MAE response: $K=132.6 \pm 11.2 \mathrm{mg} R A / g$ plant $\mathrm{dw}$; $m=57.5 \pm 7.1 \mathrm{~g}$ plant $\mathrm{dw} / \mathrm{L} ; v=0.797 \pm 0.32 \mathrm{mg} \mathrm{RA} / \mathrm{g}$ plant $\mathrm{dw}$ per g plant dw/L; $\mathrm{R}^{2}=0.9929$; and $a=1.0 \pm 0.1$.

In statistical terms, the mathematical model of Eq. (2) used to assess non-linear $S / L$ trends showed highly significant parameters for all techniques, a fact that was also verified by the achieved high $\mathrm{R}^{2}$ values, indicating the good agreement of the model with the produced experimental results. From this parametric analysis, the different trends of the $S / L$ effect can be determined at the optimal extraction conditions achieved for each one of the assessed techniques. By means of the most relevant parameters $(K, m$ and $v$ ), the following outcomes can be derived:

- For the parametric value of $K$ : the technique which provided the higher RA extraction yield was UAE followed by MAE and HAE.

- For the parametric value of $m$ : the technique that needed the lower $S / L$ values at $50 \%$ of the response was HAE followed by UAE and MAE.

- For the parametric value of $v$ : the technique which provided the lower average extraction rate values was HAE followed by MAE and UAE.

Consequently, the dose-response in terms of the response criterion $Y_{1}$ (mg RA/g plant $\mathrm{dw}$ ) can be explained by the parametric results derived from Eq. (2) and (3), and this trend was visually interpreted in Fig. 3B2, for comparison purposes, in which the modelling predictions obtained for each technique are represented jointly up to the determined experimental limit value of $120 \mathrm{~g} / \mathrm{L}$. It can be observed that UAE is the technique were higher RA yields are achieved in the $\mathrm{S} / \mathrm{L}$ interval range of $0-50 \mathrm{~g} / \mathrm{L}$, as corroborated by the higher values of parameter $K$. However, the decrease observed for the UAE system are slightly higher than for the MAE and HAE process, as noted by the parameters $m$ and $v$. In fact, the HAE system is more efficient to extract RA at $S / L$ ranges of 50 to $100 \mathrm{~g} / \mathrm{L}$. The higher loss induced by the increase of $\mathrm{S} / \mathrm{L}$ for the UAE system causes a higher dose-response (> $100 \mathrm{~g} / \mathrm{L})$ and the extraction yields are better with the HAE and MAE systems. A similar behaviour was found for the other response criteria $\left(Y_{2}\right.$ and $Y_{3}$, data not showed), considering the same variation magnitude for both.

\subsection{Comparison with other studies involving the extraction of rosmarinic acid}

In the literature, there are several techniques that also describe the extraction of RA from M. officinalis. The most relevant are supercritical carbon dioxide extraction, liquid $\mathrm{CO}_{2}$ extraction, UAE, MAE and HAE [38-40]. There are few works that compare the conventional and alternative extraction techniques $[10,17,35]$. In a previous study Ince et al. [17], the extraction of RA from the leaves of lemon balm was formulated through three techniques (HAE UAE and MAE) using water as solvent. This study revealed a higher yield for MAE followed by UAE and HAE. These results are in opposition to the results described in this manuscript where UAE was more efficient. This may be because in the herein work the proportion of the hydro-alcoholic mixtures was included as variable. This fact is corroborated by the results found by other authors dealing with the extraction of RA: a) Kim et al. [10], reported better RA extraction yields with hydro-alcoholic mixtures (methanol-based); b) Bellumori et al. [20], found that MAE and UAE using water:ethanol mixtures or water:acetone mixtures considerably increase the archived yields (using $R$. officinalis L.) comparatively with more traditional used solid-liquid extraction processes; c) Bernatoniene et al. [41], described that UAE with $90 \%$ ethanol would increase the RA extraction yield from rosemary leaves; and d) even when other techniques, such as supercritical $\mathrm{CO}_{2}$ extraction, were used to extract RA, hydro-alcoholic mixtures with $70 \%$ ethanol were reported to produce the better results [42].

M. officinalis leaf is standardized to contain not less than $4 \%$ of total hydroxycinnamic acid derivatives expressed as RA [13]. However, several studies in literature reporting the total amount of RA extracted from different species, shows some variability. In vitro cultured and in commercial samples of M. officinalis infusions, Barros et al. [1], found that RA was the most abundant compound, being higher in commercial samples, especially in tea bag samples $(55.68 \mathrm{mg} / \mathrm{g} \mathrm{dw})$ and lower in in vitro culture samples $(15.46 \mathrm{mg} / \mathrm{g}$ dw). Other authors using a variety of $M$. officinalis grown in Slovakia found $17.03 \mathrm{mg} / \mathrm{g}$ dw of RA [12]. In a study analysing commercial herbal teas containing $M$. officinalis leaves, authors indicated that, depending on the supplied source, variations from 5.2 to $32.6 \mathrm{mg} / \mathrm{g} \mathrm{dw}$ of RA were found [13]. Ince et al. [17], using MAE and UAE extraction processes with $M$. officinalis leaves found $39.8 \mathrm{mg} \mathrm{RA} / \mathrm{g} \mathrm{dw}$. To the best of our knowledge, the highest content reported in literature, from leaf material of $M$. officinalis extracted in aqueous ethanol using medium pressure liquid-solid extraction, was $96.41 \mathrm{mg} \mathrm{RA} / \mathrm{g} \mathrm{dw}$ [43].

For comparison purposes, some authors have studied the possibility of obtaining RA from six different plants using UAE, concluding that Hypericum perforatum was the plant providing the highest RA yield $(0.99 \mathrm{mg} / \mathrm{g} \mathrm{dw})$, followed by $M$. officinalis $(0.62 \mathrm{mg} / \mathrm{g} \mathrm{dw})$ and $R$. officinalis $(0.51 \mathrm{mg} / \mathrm{g} \mathrm{dw})$ [35]. Bellumori et al. [20], using $R$. officinalis reported the value of $67.7 \mathrm{mg} / \mathrm{g} \mathrm{dw}$ (UAE), and a much lower one with MAE $(32.9 \mathrm{mg} / \mathrm{g} \mathrm{dw})$.

Several factors may have contributed to the achieved variability. The most relevant one could be the lack of optimization approaches, specifically in what concerns RA extraction optimization. Authors report the extracting values under conditions not properly optimized, or by studying variables not adequately 
selected. Other reasons could be ascribed to the use of different techniques and solvents, to the use of different plant species (i.e. M. officinalis and R. officinalis), regional varieties and gathering conditions. This last point was studied in some works by using a large time-period collection, i.e. samples of $M$. officinalis collected over several years and over different seasons [44,45].

\section{Conclusions}

RA extraction from $M$. officinalis leaves was optimized using three different extraction techniques (HAE, UAE and MAE) and the obtained results were compared. The combined effects of three independent variables ( $t, T$ and $S$ for HAE and MAE, and for the UAE the $P$ was used instead of $T$ ) were studied to maximize the three response value formats $\left(Y_{1}, \mathrm{mg} \mathrm{RA} / \mathrm{g}\right.$ plant $\mathrm{dw} ; Y_{2}, \mathrm{mg} \mathrm{RA} / \mathrm{g}$ $\mathrm{R}$; and $Y_{1} / Y_{2}$, g R/g plant dw). RSM methodology was applied using a CCCD of three factors with five-levels and second-order polynomial models, which were successfully designed and experimentally verified, showing that the studied variables have significant effects on the RA extraction yield. UAE was found to be the most effective method, capable of yielding $86.3 \pm 4.1 \mathrm{mg} \mathrm{RA} / \mathrm{g}$ plant $\mathrm{dw}$ and $0.517 \pm 0.07 \mathrm{~g} R / \mathrm{g}$ plant $\mathrm{dw}$, extract comprising a content of $178.5 \mathrm{mg} \mathrm{RA} / \mathrm{g} \mathrm{R}$. These results were achieved at the following optimal extraction conditions: $33.0 \pm 3.2 \mathrm{~min}, 371.7 \pm 19.3 \mathrm{~W}$ and $39.9 \pm 1.4 \%$ of ethanol. Comparatively, MAE and HAE lead to results generally inferior, for all the assessed responses. Although MAE was found to be a much faster technique, considerably faster than HAE and slightly faster than UAE, lower RA extraction yields and extracts with lower content of RA were obtained.

Considering the study of the solid/liquid ratio effect, an important variable from an industrial point of view, the optimal values in the dose-response format have shown a decreasing non-linear correlation from 5 to $120 \mathrm{~g} / \mathrm{L}$. In terms of response criterion $Y_{1}$ (mg RA/g plant dw), it was observed that the UAE was the technique conducting to higher RA extraction yields in the $S / L$ range of $0-50 \mathrm{~g} / \mathrm{L}$. Nevertheless, for the medium $S / L$ range, HAE extraction was more efficient and for $S / L$ values higher than $100 \mathrm{~g} / \mathrm{L}, \mathrm{HAE}$ and MAE systems revealed both to be more efficient.

In all cases, the used mathematical models (RSM and doseresponse models) can be assumed as adequate models to optimize the process of RA extraction from $M$. officinalis, resulting in extracts enriched in RA. These extracts constitute interesting natural ingredients, able to substitute synthetic-derived counterparts, and with application in a wide range of industrial fields (food, pharmaceutical and cosmetic applications).

This work offers an overview through the use of environmentally compatible extraction processes, and the obtained results indicate the viability of using $M$. officinalis leaves as a productive source to obtain RA-enriched extracts, which may constitute interesting approaches to be transposed to a large productive scale.

\section{Acknowledgements}

The authors are grateful to the Foundation for Science and Technology (FCT, Portugal) and FEDER under Programme PT2020 for financial support to CIMO (UID/AGR/00690/2013), REQUIMTE (UID/QUI/50006/2013 - POCI/01/0145/ FEDER/007265) and Caleja (SFRH/BD/93007/2013) and L. Barros (SFRH/BPD/107855/2015) grants. This work was also financially supported by: Project POCI-01-0145-FEDER-006984 - Associate Laboratory LSRE-LCM funded by FEDER through COMPETE2020 - Programa Operacional Competitividade e Internacionalização (POCI) - and by national funds through FCT - Fundação para a Ciência e a Tecnologia. To Xunta de Galicia for financial support for the post-doctoral researcher of M.A. Prieto. The authors also thank to company Mais
Ervas, Lda (Alfandega da Fé, Portugal), for providing the M. officinalis samples.

\section{Appendix A. Supplementary material}

Supplementary data associated with this article can be found, in the online version, at http://dx.doi.org/10.1016/j.seppur.2017.06. 029.

\section{References}

[1] L. Barros, M. Dueñas, M.I. Dias, M.J. Sousa, C. Santos-Buelga, I.C.F.R. Ferreira, Phenolic profiles of cultivated, in vitro cultured and commercial samples of Melissa officinalis L. infusions, Food Chem. 136 (2013) 1-8.

[2] M. Carocho, L. Barros, R.C. Calhelha, A. Ćirić, M. Soković, C. Santos-Buelga, P. Morales, I.C.F.R. Ferreira, Melissa officinalis L. decoctions as functional beverages: a bioactive approach and chemical characterization, Food Funct. 6 (2015) 2240-2248.

[3] A. Shakeri, A. Sahebkar, B. Javadi, Melissa officinalis L. - a review of its traditional uses, phytochemistry and pharmacology, J. Ethnopharmacol. 188 (2016) 204-228.

[4] C. Weidner, S.J. Wowro, A. Freiwald, V. Kodelja, H. Abdel-Aziz, O. Kelber, S. Sauer, Lemon balm extract causes potent antihyperglycemic and antihyperlipidemic effects in insulin-resistant obese mice, Mol. Nutr. Food Res. 58 (2014) 903-907.

[5] Y. Birdane, M. Büyüjokuroglu, F. Birdane, M. Cemek, H. Yavuz, Antiinflammatory and antinociceptive effects of Melissa officinalis L. in rodents, Rev. Med. Vet. (Toulouse). 158 (2007) 75-81.

[6] R. Guimarães, L. Barros, R.C. Calhelha, A.M. Carvalho, M.J.R.P. Queiroz, I.C.F.R. Ferreira, Bioactivity of different enriched phenolic extracts of wild fruits from Northeastern Portugal: a comparative study, Plant Foods Hum. Nutr. 69 (2014) 37-42.

[7] V. López, S. Martín, M.P. Gómez-Serranillos, M.E. Carretero, A.K. Joger, M.I. Calvo, Neuroprotective and neurological properties of Melissa officinalis, Neurochem. Res. 34 (2009) 1955-1961.

[8] A. Santos, L. Barros, R.C. Calhelha, M. Duenas, A.M. Carvalho, C. Santos-buelga, I. C.F.R. Ferreira, Leaves and decoction of Juglans regia L.: Different performances regarding bioactive compounds and in vitro antioxidant and antitumor effects, Ind. Crop. Prod. 51 (2013) 430-436.

[9] H. Moradkhani, E. Sargsyan, H. Bibak, B. Naseri, H. Meftahizade, Melissa officinalis L., a valuable medicine plant : a review, J. Med. Plants. 4 (2010) 2753-2759.

[10] S. Kim, E.J. Yun, J.S. Bak, H. Lee, K.H. Kim, Response surface optimised extraction and chromatographic purification of rosmarinic acid from Melissa officinalis leaves, Food Chem. 121 (2010) 521-526.

[11] M. Carocho, P. Morales, I.C.F.R. Ferreira, Natural food additives: Quo vadis?, Trends Food Sci Technol. 45 (2015) 284-295.

[12] A. Caniova, E. Brandsteterova, HPLC analysis of phenolic acids in Melissa officinalis, J. Liq. Chromatogr. Relat. Technol. 24 (2001) 2647-2659.

[13] I. Fecka, S. Turek, Determination of water-soluble polyphenolic compounds in commercial herbal teas from Lamiaceae: peppermint, melissa, and sage, J. Agric. Food Chem. 55 (2007) 10908-10917.

[14] P. Pillai, K. Ramaswamy, Effect of naturally occurring antimicrobials and chemical preservatives on the growth of Aspergillus parasiticus, J. Food Sci. Technol. 49 (2012) 228-233.

[15] J. Dai, R.J. Mumper, Plant phenolics: extraction, analysis and their antioxidant and anticancer properties, Molecules 15 (2010) 7313-7352.

[16] K.N. Lokesh, Channarayappa, M. Venkatarangana, Exemplified screening standardization of potent antioxidant nutraceuticals by principles of design of experiments, J. Funct. Foods. 17 (2015) 260-270.

[17] A.E. Ince, S. Sahin, S.G. Sümnü, Extraction of phenolic compounds from melissa using microwave and ultrasound, Turkish J. Agric. For. 37 (2013) 69-75.

[18] F. Chemat, N. Rombaut, A. Sicaire, A. Meullemiestre, M. Abert-vian, Ultrasonics Sonochemistry Ultrasound assisted extraction of food and natural products. Mechanisms, techniques, combinations, protocols and applications. A review, Ultrason. - Sonochemistry. 34 (2017) 540-560.

[19] F. Chemat, Zill-E-Huma, M.K. Khan, Applications of ultrasound in food technology: processing, preservation and extraction, Ultrason. Sonochem. 18 (2011) 813-835

[20] M. Bellumori, M. Innocenti, A. Binello, L. Boffa, N. Mulinacci, G. Cravotto, Selective recovery of rosmarinic and carnosic acids from rosemary leaves under ultrasound-and microwave-assisted extraction procedures, Comptes Rendus Chim. 19 (2016) 699-706.

[21] F. Dahmoune, B. Nayak, K. Moussi, H. Remini, K. Madani, Optimization of microwave-assisted extraction of polyphenols from Myrtus communis L. leaves, Food Chem. 166 (2015) 585-595.

[22] J. Pinela, M.A. Prieto, A.M. Carvalho, L. Barros, A. Maria, M. Filomena, I.C.F.R. Ferreira, Microwave-assisted extraction of phenolic acids and flavonoids and production of antioxidant ingredients from tomato: a nutraceutical-oriented optimization study, Sep. Purif. Technol. 164 (2016) 114-124.

[23] J. Pinela, L. Barros, A.L. Antonio, A. Carvalho, M.B.P.P. Oliveira, I.C.F.R. Ferreira, Quality control of gamma irradiated dwarf mallow (Malva neglecta Wallr.) based on color, organic acids, total phenolics and antioxidant parameters, Molecules 21 (2016) 467, http://dx.doi.org/10.3390/molecules21040467. 
[24] S.L.C. Ferreira, R.E. Bruns, H.S. Ferreira, G.D. Matos, J.M. David, G.C. Brandão, E. G.P. da Silva, L.A. Portugal, P.S. dos Reis, A.S. Souza, W.N.L. dos Santos, BoxBehnken design: an alternative for the optimization of analytical methods, Anal. Chim. Acta. 597 (2007) 179-186.

[25] M.A. Bezerra, R.E. Santelli, E. P. Oliveira, L.S. Villar, E.A. Escaleira, L. A. Escaleira, Response surface methodology (RSM) as a tool for optimization in analytical chemistry, Talanta 76 (2008) 965-977.

[26] S.M.F. Bessada, J.C.M. Barreira, L. Barros, I.C.F.R. Ferreira, M.B.P.P. Oliveira, Phenolic profile and antioxidant activity of Coleostephus myconis (L.) Rchb.f.: An underexploited and highly disseminated species, Ind. Crops Prod. 89 (2016) 45-51.

[27] G.E.P. Box, J.S. Hunter, W. G. Hunter, W.G. Hunter, Statistics for Experimenters: Design, Innovation, and Discovery, 2005.

[28] J. Pinela, M.A. Prieto, A.M. Carvalho, M.F. Barreiro, M.B.P.P. Oliveira, L. Barros, I. C.F.R. Ferreira, Microwave-assisted extraction of phenolic acids and flavonoids and production of antioxidant ingredients from tomato: a nutraceuticaloriented optimization study, Sep. Purif. Technol. 164 (2016) 114-124.

[29] S.A. Heleno, P. Diz, M.A. Prieto, L. Barros, A. Rodrigues, M.F. Barreiro, I.C.F.R. Ferreira, Optimization of ultrasound-assisted extraction to obtain mycosterols from Agaricus bisporus L. by response surface methodology and comparison with conventional Soxhlet extraction, Food Chem. 197 (2016) 1054-1063.

[30] B.R. Albuquerque, M.A. Prieto, M.F. Barreiro, A. Rodrigues, T.P. Curran, L. Barros, I.C.F.R. Ferreira, Catechin-based extract optimization obtained from Arbutus unedo L. fruits using maceration/microwave/ultrasound extraction techniques, Ind. Crops Prod. 95 (2016) 404-415.

[31] M.A. Murado, M.A. Prieto, NOEC and LOEC as merely concessive expedients: two unambiguous alternatives and some criteria to maximize the efficiency of dose-response experimental designs, Sci. Total Environ. 461-462 (2013) 576586.

[32] M.A. Murado, M.A. Prieto, Dose-response analysis in the joint action of two effectors. A new approach to simulation, identification and modelling of some basic interactions, PLoS One 8 (2013) e61391.

[33] M.A. Prieto, J. Vázquez, Time-Dose Model to Quantify the Antioxidant Responses of the Oxidative Hemolysis Inhibition Assay (OxHLIA) and Its Extension to Evaluate Other Hemolytic Effectors, Biomed Res. Int. 2014 (2014) 15 pages.

[34] C. Comuzzi, P. Polese, A. Melchior, R. Portanova, M. Tolazzi, SOLVERSTAT: a new utility for multipurpose analysis. An application to the investigation of dioxygenated Co (II) complex formation in dimethylsulfoxide solution, Talanta 59 (2003) 67-80.

[35] M. Nicolai, P. Pereira, R.F. Vitor, C.P. Reis, A. Roberto, P. Rijo, Antioxidant activity and rosmarinic acid content of ultrasound-assisted ethanolic extracts of medicinal plants, Measurement 89 (2016) 328-332.

[36] S. Rodríguez-Rojo, A. Visentin, D. Maestri, M.J. Cocero, Assisted extraction of rosemary antioxidants with green solvents, J. Food Eng. 109 (2012) 98-103.

[37] M.A. Prieto, J.A. Vázquez, M.A. Murado, A new mathematical model to quantify and characterize the response to pro- and anti-oxidants of the copper-induced oxidation of LDL assay. A tool for examination of potential preventive compounds and clinical risk prediction, Food Res. Int. 66 (2014) 501-513.

[38] P. Garcia-Salas, A. Morales-Soto, A. Segura-Carretero, A. Fernández-Gutiérrez Phenolic-compound-extraction systems for fruit and vegetable samples, Molecules 15 (2010) 8813-8826.

[39] P. Bajerová, M. Adam, T. Bajer, K. Ventura, Comparison of various techniques for the extraction and determination of antioxidants in plants, J. Sep. Sci. 37 (2014) 835-844.

[40] A. Bogdanovic, V. Tadic, I. Arsic, S. Milovanovic, S. Petrovic, D. Skala, Supercritical and high pressure subcritical fluid extraction from Lemon balm (Melissa officinalis L., Lamiaceae), J. Supercrit. Fluids 107 (2016) 234-242.

[41] J. Bernatoniene, U. Cizauskaite, L. Ivanauskas, V. Jakstas, Z. Kalveniene, D.M. Kopustinskiene, Novel approaches to optimize extraction processes of ursolic oleanolic and rosmarinic acids from Rosmarinus officinalis leaves, Ind. Crops Prod. 84 (2016) 72-79.

[42] A.W. Zibetti, A. Aydi, M.A. Livia, A. Bolzan, D. Barth, Solvent extraction and purification of rosmarinic acid from supercritical fluid extraction fractionation waste: economic evaluation and scale-up, J. Supercrit. Fluids. 83 (2013) 133145.

[43] K. Dastmalchi, H.J. Damien Dorman, P.P. Oinonen, Y. Darwis, I. Laakso, R Hiltunen, Chemical composition and in vitro antioxidative activity of a lemon balm (Melissa officinalis L.) extract, LWT - Food Sci. Technol. 41 (2008) 391 400.

[44] D. Argyropoulos, J. Müller, Kinetics of change in colour and rosmarinic acid equivalents during convective drying of lemon balm (Melissa officinalis L.), J. Appl. Res. Med. Aromat. Plants. 1 (2014) e15-e22.

[45] U. Bomme, F. Pank, R. Rinder, Content of rosmarinic acid and winter hardiness in lemon balm (Melissa officinalis L.) - Results of investigations from a large collection, Rosmarinsäuregehalt Und Winterhärte Bei Zitr. (Melissa Off. L) Ergebnisse Aus Einer Großen Sortimentsprüfung. 13 (2008) 65-71. 